\title{
Effects of urokinase-type plasminogen activator in the acquisition, expression and reinstatement of cocaine-induced conditioned-place preference
}

\author{
Amine Bahi ${ }^{\mathrm{a}, 1}$, Alexander W. Kusnecov ${ }^{\mathrm{b}}$, Jean-Luc Dreyer ${ }^{\mathrm{a}, *}$ \\ a Division of Biochemistry, Department of Medicine, University of Fribourg, Chemin du Musée 5, CH-1700 Fribourg, Switzerland \\ ${ }^{\mathrm{b}}$ Department of Psychology, Rutgers University, 152 Frelinghuyen Road, Piscataway, NJ 08854, USA
}

Keywords: Addiction Cocaine

Conditioned-place preference

Drug reinstatement

In vivo gene transfer

Lentivirus

Urokinase

siRNA

\begin{abstract}
A B S T R A C T
Cocaine and many other psychostimulants strongly induce urokinase-type plasminogen activator (uPA) expression in the mesolimbic dopaminergic pathway, which plays a major role in drug-mediated behavioral plasticity [Bahi A, Boyer F, Gumy C, Kafri T, Dreyer JL. In vivo gene delivery of urokinase-type plasminogen activator with regulatable lentivirus induces behavioral changes in chronic cocaine administration. Eur J Neurosci 2004;20:3473-88; Bahi A, Boyer F, Kafri T, Dreyer JL. Silencing urokinase in the ventral tegmental area in vivo induces changes in cocaine-induced hyperlocomotion. J Neurochem 2006;98:1619-31; Bahi A, Dreyer JL. Overexpression of plasminogen activators in the nucleus accumbens enhances cocaine-, amphetamine- and morphine-induced reward and behavioral sensitization. Genes Brain Behav 2007]. In this study, the role of mesolimbic dopamine (DA) pathways in the development of cocaine reward was examined by conditioned-place preference in rats with bilateral intra-accumbens injections of uPA-expressing lentiviral vectors. We show that overexpression of uPA in the Nac significantly augments cocaine-induced place preference. Furthermore, while this did not affect the ability of preference to be extinguished, reinstatement with a low dose of cocaine produced significantly greater preference to the cocaine-associated context. Once CPP had been established, and the preference extinguished, reinstatement induced by a priming dose of cocaine was facilitated by uPA. Inhibition of this serine protease expression using doxycycline abolished the augmented acquisition produced by overexpression of uPA but not the expression of the cocaine-induced CPP. When uPA is inhibited during the acquisition phase, animals no longer demonstrate place preference for the environment previously paired with cocaine. B428, a specific uPA inhibitor does not affect drug reinstatement after extinction if uPA has been activated during acquisition, a clear indication that uPA is involved in the acquisition phase of conditioned-place preference. Our results suggest that that increased uPA expression with repeated drug exposure produces conditions for enhanced acquisition of cocaine-induced CPP, indicating that cocaine-induced CPP and reinstatement may be dependent on active extracellular uPA.
\end{abstract}

\section{Introduction}

Plasminogen activators are important mediators of extracellular metabolism, involved in remodeling events during development and regeneration in the nervous system. The generation of plas-

Abbreviations: CPP, cocaine-induced conditioned-place preference; $\mathrm{CPu}$, caudate putamen; GFP, green fluorescent protein; HEK293T, human embryonic kidney 293T cells; Hipp, hippocampus; NAc, nucleus accumbens; PAI-1, inhibitor-1 of plasminogen activator; siRNA, small interfering RNA; SNr, substantia nigra; tPA, tissue-type plasminogen activator; uPA, urokinase-type plasminogen activator; uPAR, receptor of uPA; VTA, ventral tegmental area.

* Corresponding author. Tel.: +4126300 8632; fax: +41263009735.

E-mail address: jean-luc.dreyer@unifr.ch (J.-L. Dreyer).

1 Present address: Department of Psychiatry, Yale University School of Medicine, 301 Cedar Street, New Haven, CT 06508, USA. min from its inactive precursor plasminogen, is mediated by serine enzymes known as tissue-type plasminogen activator (tPA) and urokinase (uPA), and contributes to the turnover of the extracellular matrix in the central nervous system [1]. Urokinase-type plasminogen activator (UPA) exerts a variety of functions during development, and is involved in learning and memory. Expression of UPA and its receptor, uPAR, may play an important role for synaptogenesis, remodeling, and reactive processes other than for cell migration in developing mouse brain [2]. Activity-dependent synaptic plasticity and remodeling of the mesolimbic dopaminergic system play a crucial role in the development of drug dependence [3-6]. It is well established that drugs of abuse, including the stimulants cocaine and metamphetamine, as well as morphine, acutely modulate the activity of mesolimbic dopaminergic neurons, projecting from the ventral tegmental area (VTA) of the midbrain to the nucleus accumbens (NAc) [7-11]. Consistent with its hypoth- 
esized role in plasticity, uPA expression is strongly induced in the mesolimbic dopaminergic pathway in response to psychostimulant treatment [12]. In turn, uPA induces strong behavioral changes associated with drug delivery. For example, metamphetamineinduced dopamine release in the nucleus accumbens recruits the plasminogen activator-plasmin system [13], inducing long-term synaptic plasticity and remodeling, and increasing drug-induced reward $[14,15]$. The plasmin system also participates in the rewarding effects of morphine by acutely regulating morphine-induced dopamine release in the nucleus accumbens (NAc) $[13,16]$. A single morphine treatment induced tPA expression in the NAc in a naloxone-sensitive manner, with tPA expression diminishing after repeated morphine administration. Conversely, morphine-induced conditioned-place preference and hyperlocomotion were significantly reduced in tPA and plasminogen knockout mice, along with an accompanying loss of dopaminergic reactivity in the NAc [16,17].

We have previously shown that genetic manipulation of uPA expression in rats' results in altered reactivity to cocaine administration. Lentiviral-mediated overexpression of uPA in the VTA of rats increases doxycycline-dependent expression of its receptor, uPAR, but not its inhibitor, plasminogen activator inhibitor-1 (PAI-1) [18]. The expression of uPAR in the VTA is repressed upon silencing of UPA with lentiviruses expressing siRNAs [18]. Associated with the overexpression of uPA in the VTA is a 10 -fold increase in locomotor activity following injection of cocaine [12]. However, animals expressing the dominant-negative form of uPA failed to display such hyperlocomotor activity [12]. These cocaine-induced behavioral changes, associated with uPA expression, could be suppressed in the presence of doxycycline or of siRNA targeted against uPA $[18,19]$. Collectively, these and other data [13] strongly support a major role for urokinase in psychostimulant-mediated plasticity changes.

In the present study, we extended our previous observations $[12,18,19]$ by assessing the role of accumbal uPA overexpression on the reinforcing properties of cocaine in the conditioned-place preference (CPP) paradigm. Animals were injected into the nucleus accumbens with lentiviruses expressing uPA, and various parameters of place preference conditioning were assessed. We show that uPA expression was important for the acquisition, but not expression of CPP. In addition, when uPA was inhibited during acquisition, animals displayed a memory deficit and no longer associated the environment with cocaine. After extinction, priming with low doses of cocaine reinstated place preference, but reinstatement of place preference was strongly facilitated upon uPA expression. These data confirm that the plasmin system plays an important function in the expression of drug dependence, mainly through activation of extracellular proteases, e.g. uPA.

\section{Materials and methods}

\subsection{Animals}

Animals used in this experiment were male Wistar rats weighing $220-250 \mathrm{~g}$. All animal experiments were carried out in accordance with the guidelines and regulations for Animal Experimentation, BAG, Bern, Switzerland. The animals were housed in trios in clear plastic cages with wire grid lids. Access to food and water was unrestricted. The animals were kept in the animal facility maintained on a $12-\mathrm{h}$ light:12-h dark cycle (light off at 7 a.m.).

\subsection{Lentivirus construction of $L V$ - $u P A$ and $L V$-GFP}

Briefly, the rat uPA cDNA was amplified by reverse transcription using superscript II reverse transcriptase (Invitrogen, Switzerland) following the manufacturer's instructions. The cDNA was then PCR amplified, 6 His-tagged, digested with BamHI and Xhol and cloned into similar sites in pTK431 $[12,18,19]$. A control vector construct, pTK433 in which green fluorescent protein (GFP) expression is regulated by a tetracycline inducible promoter, was generated by cloning a BamHI/BglII DNA fragment containing the GFP gene into a BamHI site in pTK431 [12,18,19-22]. All plasmids were $\mathrm{CsCl}_{2}$ purified.

Vesicular stomatitis virus $\mathrm{G}$ pseudo-typed lentiviruses were produced by the transient calcium phosphate co-transfection of HEK293T cells with pTK vectors together with pMDG-VSV-G and p $\Delta$ NRF as previously described [12,18-23]. Lentiviral vector quantifications were performed according to the p24 ELISA (KPL, USA) in accordance with the manufacturer's instructions.

\subsection{Surgery}

All surgical procedures were performed as previously described [12,18-22]. Briefly, rats were anesthetized with a mix of ketamine/xylazine $(100 \mathrm{mg} / \mathrm{kg} /$ $10 \mathrm{mg} / \mathrm{kg}$, i.p.). Using a $5-\mu \mathrm{l}$ Hamilton syringe, $2 \mu \mathrm{l}$ of concentrated lentiviral solutions mix (ca. $200.000 \mathrm{ng}$ of p24 antigen $/ \mathrm{ml}$ ) per site were bilaterally injected into the NAc or the dorsal striatum-, at the corresponding coordinates (NAc: anterior, +1.4 ; lateral, \pm 1.6 ; ventral, -6.8 ; dorsal striatum: anterior, +0.7 ; lateral, \pm 3.2 ; ventral, -4.5 [24]), with a rate of $1 \mu \mathrm{l} / \mathrm{min}$, in a stereotaxic frame. The needle was then left in place for an additional $5 \mathrm{~min}$ and gently withdrawn. After surgery, animals were injected subcutaneously with $5 \mathrm{ml}$ of pre-warmed saline to avoid animal dehydration. Animals were left 7 days to recover prior to experimentation.

\subsection{Conditioned-place preference test}

Conditioned-place preference was performed as previously described $[25,26]$. Briefly, in the pre-conditioning period, rats were allowed to move freely between two interconnected chambers (consisting of either wire grid or mesh floor) daily for 20 min for 3 days (days $1-3$ ). On day 3 , the amount of time spent in each chamber was monitored and used to assess unconditioned preferences. Prior to conditioning, the rats were divided into three groups ( $n=9 /$ group). The first group of animals was fed water supplemented with $5 \%$ sucrose, the second group of animals received water supplemented with $5 \%$ sucrose and $0.02 \%$ doxycycline during conditioning "Acquisition" (days 3-9) and the third group of animals was fed with the same solution during the post-conditioning "Expression" (day 10). We have shown previously that when removed from the drinking water, doxycycline was significantly eliminated within $24 \mathrm{~h}$. Furthermore, when given to animals, doxycycline fully inhibits ectopic gene expression in the same period of time $[12,18,19]$. During the conditioning phase, rats were injected with cocaine $(20 \mathrm{mg} / \mathrm{kg}$, i.p.; $n=9 /$ group $)$ on days 4,6 , and 8 and immediately confined in the floor-mesh box for $20 \mathrm{~min}$. It is well established that CPP for cocaine develops in both rats and mice when injected with cocaine $20 \mathrm{mg} / \mathrm{kg}$ [25,27-34]. On days 5, 7, and 9, rats were injected with $0.9 \%$ saline $(1 \mathrm{ml} / \mathrm{kg})$ and placed in the wire grid chamber for $20 \mathrm{~min}$. During the conditioning phase, a guillotine door blocked access between the two chambers. On day 10 , the post-conditioning "CPP" test was performed without drug treatment. Animals were placed between the two chambers with the guillotine door removed and allowed free access to the entire set-up. The time spent in each chamber was measured for $20 \mathrm{~min}$. Drug-induced place preference was expressed in seconds of preference for pre- and post-conditioning, measured as time spent at the drug-conditioning site during each conditioning periods.

\subsubsection{Extinction}

After conditioning and following the initial CPP test, rats ( $n=9 /$ group) underwent 20 min tests daily for 10 days, but no injections were performed. Complete extinction of CPP in cocaine-conditioned animals, defined as the return to exploratory times that did not differ significantly from saline-injected control animals, was determined as the amount of time spent in each chamber being equivalent to that of saline-injected control animals.

\subsubsection{Reinstatement by cocaine priming after extinction}

Animals were subjected to extinction as just described. Once complete extinction was established, animals ( $n=9 /$ group) either received a priming i.p. injection of $0.9 \%$ saline $(1 \mathrm{ml} / \mathrm{kg}$ ) or cocaine $(2 \mathrm{mg} / \mathrm{kg}$ ) immediately prior to a final CPP test.

In experiments involving B428, a specific uPA inhibitor [35-37], animals ( $n=9 /$ group) were injected with B428 (30 mg/kg, i.p.) in their home cage. $30 \mathrm{~min}$ later, rats were injected with saline or $\mathrm{r}$ cocaine $(2 \mathrm{mg} / \mathrm{kg}$, i.p. if uPA was blocked during priming experiments, or $15 \mathrm{mg} / \mathrm{kg}$ in experiments where uPA had been inhibited during conditioning), immediately prior to the final CPP test ( 20 min session).

\subsubsection{Maintenance of CPP following withdrawal}

After CPP testing, rats ( $n=9 /$ group) underwent a 5-week period of withdrawal during which animals were not handled, injected nor exposed to the conditioning apparatus, but remained in their home cages. After this period, rats were placed in the conditioning apparatus and allowed free access to both compartments for $20 \mathrm{~min}$.

\subsection{Gel zymography}

SDS-PAGE zymography was performed as described previously [19]. Briefly, rats were sacrificed $24 \mathrm{~h}$ after the last recording of the behavioral experiments. Brains were quickly removed and NAc regions were rapidly dissected and used for protein extraction. The tissue was homogenized and protein concentrations were measured using the Bradford method. Equal amounts of protein extracts $(10 \mu \mathrm{g})$ were mixed with non-reducing SDS-PAGE sample buffer and run in a 10\% SDS-PAGE gel containing $0.1 \%$ casein (Sigma, Switzerland) and $12 \mathrm{mU} / \mathrm{ml}$ plasminogen (Calbiochem, 

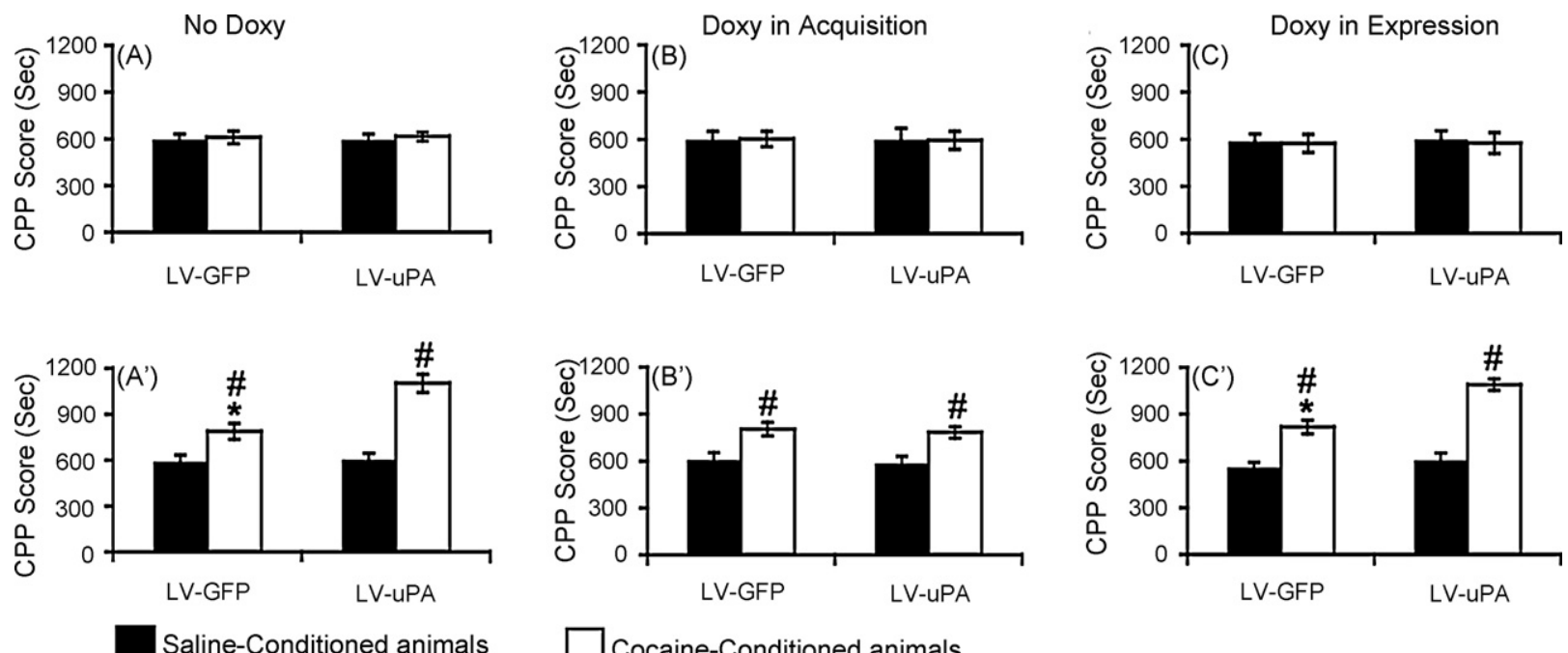

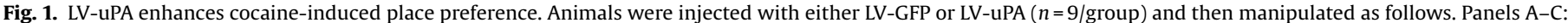

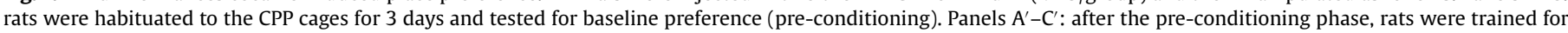

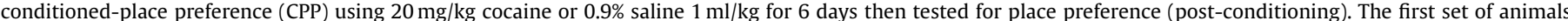

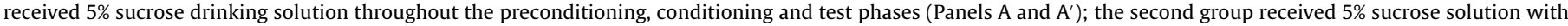

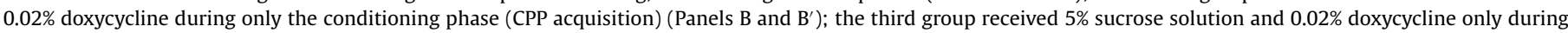

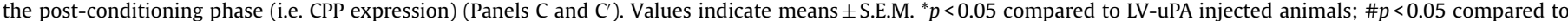
saline-conditioned animals.

Switzerland). After electrophoresis the gel was washed and was then incubated overnight in $100 \mathrm{mM}$ Tris- $\mathrm{HCl}, \mathrm{pH} 8.1$ and $15 \mathrm{mM} \mathrm{MgCl}_{2}$ solution at $37^{\circ} \mathrm{C}$, stained with Coomassie Brilliant Blue (Sigma, Switzerland) and destained with solution containing 35\% methanol, $7 \%$ acetic acid. uPA activity was then observed in the gel as light bands against a dark background.

\subsection{Immunohistochemistry}

Brain section staining was performed according to previously published procedures $[12,18,19]$. Briefly, rats were sacrificed $24 \mathrm{~h}$ after the last recording of the behavioral experiments, brains were rapidly removed, frozen, and coronal sections obtained on a cryostat. Slices were fixed in $4 \%$ PFA for $15 \mathrm{~min}$, and washed three times with $1 \times$ PBS. Sections were then rinsed and incubated overnight with mouse anti-histidine antibody (MCA1396, Serotec, 1:12,000), washed and incubated with the biotinylated secondary antibody (goat anti-mouse immunoglobulin G, Vector Laboratories, Burlingame, CA, USA, 1:500). Sections were rinsed and incubated in the avidin-biotin complex (Vector Laboratories). After three rinses in $1 \times$ PBS, all sections were developed in $0.025 \% 3,3^{\prime}$-diaminobenzidine tetrahydrochloride (DAB) plus $0.02 \% \mathrm{H}_{2} \mathrm{O}_{2}$ for $10-15 \mathrm{~min}$. Sections were then dehydrated, mounted in permanent medium (Eukitt) and examined with a Zeiss light microscope.

\subsection{Statistical analysis}

All behavioral data (differences in time spent between conditioned and non-conditioned compartments) were analyzed by ANOVA using SPSS V11 software. Fundamental analysis of CPP used a three-way ANOVA ([LV-GFP/LV$\mathrm{uPA} \times$ cocaine/saline $\times$ doxy/sucrose $]$ or $[\mathrm{LV} \times$ Drug $\times$ B428/Vehicle $])$. Additional ANOVAs for the extinction phase incorporated repeated measures for the 10 days of extinction. Main and interaction effects were deemed significant at $p<0.05$ and where appropriate were followed by pairwise comparisons using the Tukey test.

\section{Results}

\subsection{Lentivirus-mediated UPA expression in the NAc affects place preference}

To determine the effects of uPA expression on cocaine-mediated place preference, animals were injected with either LV-uPA or LV-GFP into the NAc. Gene expression by both vectors is regulated by doxycycline, which was administered to separate groups of animals to determine whether uPA expression was necessary during acquisition or expression of CPP. Therefore, two separate groups of animals were fed doxycycline either during CPP acqui- sition (days 3-10), or during the expression phase of CPP (at day $10)$. A third group was given only sucrose-flavored water without doxycycline throughout all phases of the experiment. Data are summarized in Fig. 1. Before conditioning (at day 3) all animals were pretested for evidence of bias towards either compartment in the conditioning apparatus (Fig. $1 \mathrm{~A}-\mathrm{C} ; F_{(5,60)}=1.1 ; p>1.00$ ). No evidence of bias was found, since during preconditioning, rats spent the same amount of time in both chambers $\left(F_{(11,120)}=0.26\right.$; $p>0.990$ ) (see Fig. $1 \mathrm{~A}-\mathrm{C}$ ). Animals were then conditioned for place preference and tested on day 10 . Saline-conditioned animals displayed no behavioral changes, whether they were fed water or doxycycline, and their preference scores were unchanged after the conditioning phase $\left(F_{(5,60)}=1.105 ; p>0.379\right)$. However, between subjects comparisons of saline versus cocaine-treated animals showed that GFP-treated animals displayed cocaine-induced place preference $\left(F_{(5,60)}=48.81 ; p<0.005\right)$, irrespective of whether they were fed doxycycline or not (see LV-GFP groups in Fig. $1 \mathrm{~B}^{\prime}$ and $\left.1 C^{\prime}: F_{(11,60)}=41.781 ; p<0.00001\right)$. Alternatively, uPA-treated animals displayed a much higher preference for the cocaine-paired chamber $\left(F_{(5,60)}=178.94 ; p<0.001\right)$ (Fig. $\left.1 \mathrm{~A}^{\prime}\right)$ and spent approximately $90 \%$ of the time in this drug-associated chamber. However, when uPA was not expressed during the conditioning phase (i.e. if uPA-expression was inhibited by doxycycline during the acquisition period), cocaine-conditioned LV-uPA animals did not display a greater preference than the cocaine-conditioned GFP-controls ( $p>0.377$ compared to GFP; $p<0.001$ compared to preconditioning; see Fig. $\left.1 \mathrm{~B}^{\prime}\right)$. These uPA-treated animals, nevertheless, which have been fed doxycycline during conditioning, displayed significant lower scores than the corresponding group that has not been fed doxycycline (Fig. $1 \mathrm{~B}^{\prime}$ and $1 \mathrm{~A}^{\prime} ; F_{(11,60)}=41.781 ; p<0.0005$ ). However, if uPA expression was suppressed only during CPP expression (i.e. if animals were fed doxycycline only at the end of the learning period (after day 9)), cocaine-conditioned LV-uPA animals again showed approximately $90 \%$ preference for the drug-paired chamber (Fig. $1 C^{\prime} ; F_{(11,60)}=41.78 ; p<0.0001$ ). These data suggest that the enhancing effects of LV-uPA on cocaine-induced CPP are dependent on the expression of uPA during the acquisition phase of conditioning, rather than during the expression phase of CPP, when animals are tested for place preference. 


\subsection{Effect of $L V-u P A$ on extinction of $C P P$}

Animals injected with either LV-GFP or LV-uPA, were trained for conditioned-place preference, tested for CPP on day 10, and then subjected to a series of extinction trials in which they were re-exposed to the conditioning apparatus without any injections, but were allowed free-access to both chambers. As shown in Fig. 2, animals which had been conditioned with saline displayed no significant behavioral change during this extinction period, and kept spending approximately $50 \%$ of the time in both compartments, irrespective of whether they had been fed doxycycline or not during either the conditioning (acquisition) or post-conditioning (expression) phase (Fig. $2 \mathrm{~A}-\mathrm{C}$; within subject factor $F_{(5,60)}=0.17 ; p>0.971$ ). In contrast, animals which had been conditioned with cocaine displayed progressive extinction over the 10-day period (within subject factor $F_{(5,60)}=38.547 ; p<0.0001$ ). The rate of extinction among GFP-treated animals was not altered by doxycycline treatment. Between subject analysis of day 5 versus day 6 revealed no significant difference $\left(F_{(2,30)}=0.223 ; p>0.803\right.$ and $F_{(2,30)}=1.234 ; p>0.319$ for days 5 and 6 , respectively), indicating that 5-6 days after the CPP test, these GFP-treated animals were unable to distinguish between the two compartments. uPA-treated animals displayed a longer extinction latency, which lasted 7-8 days, but this was likely due to the fact that place preference was initially much higher (Fig. 2A'; between subject analysis for days 7 and 8 , respectively $F_{(2,30)}=25.57 ; p<0.001$ and $\left.F_{(2,30)}=23.64 ; p<0.001\right)$. This latter effect in uPA-treated animals was observed both in groups fed doxycycline during CPP expression and in animals not fed doxycycline (Fig. $2 \mathrm{~A}^{\prime}$ and $\mathrm{C}^{\prime}$; within subject analysis of doxycycline in expression vs. no doxycycline $p>0.06$ ). In contrast, animals fed doxycycline during the acquisition period already displayed lower place preference at the initiation of extinction, similar to GFP-treated animals, and showed an overlapping extinction rate to that observed in GFPtreated animals (see Fig. 2B'; $p>0.531$ ). Alternatively, uPA-treated animals fed doxycycline only during the expression phase displayed extinction similar to animals under the normal (no doxy) regimen (compare Fig. $2 \mathrm{C}^{\prime}$ vs. $\mathrm{A}^{\prime} ; p>0.183$ ). Finally, at the end of the extinction process (day 10) there were no differences in preference among all the groups (between subject factor $F_{(11,120)}=0.487 ; p>0.904$ ). This observation prompted us to proceed towards an assessment of the effects of cocaine priming on reinstatement of CPP.

\subsection{Reinstatement of cocaine-induced place preference following} extinction

After a 10-day extinction period, animals were given one single injection of saline or cocaine and tested for CPP. Injection of saline had no effect on reinstatement of place preference (see Fig. 3, upper panels A-C; $F_{(11,120)}=1.044 ; p>0.421$ ), irrespective of whether they had been fed doxycycline during either the acquisition phase or the expression phase of place preference conditioning (between subject factor compared to regimen: $F_{(11,60)}=41.78 ; p>0.993$ ). No change was observed neither in cocaine (between subject factor $F_{(5,60)}=1.06 ; p>0.401$ ) nor saline-conditioned animals (between subject factor $F_{(5,60)}=1.203 ; p>0.332$ ). However, if animals were given a single injection of a very low dose of cocaine ( $2 \mathrm{mg} / \mathrm{kg}$, i.p.), drug-mediated place preference was immediately re-established $\left(F_{(11,120)}=121.48 ; p<0.0001\right)$ (Fig. 3 lower panels $\mathrm{A} ; \mathrm{B}^{\prime}$ and $\left.\mathrm{C}^{\prime}\right)$. This was evident in the GFP-treated animals, who displayed a modest preference for the drug-paired compartment and spent $60 \%$ of the time in the drug compartment $\left(F_{(5,60)}=56.303 ; p<0.005\right)$, which was similar to the behavior observed before extinction $\left(F_{(11,120)}=1.198 ; p>0.308\right)$. In contrast, uPA-treated animals displayed a much stronger reinstatement of place preference, which once more showed up to $90 \%$ exploration time in the drug-paired compartment, as observed prior to extinction (Fig. 3A $\mathrm{A}^{\prime}$ and $\mathrm{C}^{\prime}$; $\left.F_{(5,60)}=175.52 ; p<0.0001\right)$. Nevertheless, the substantial magnitude of this reinstatement was not observed if animals had been fed doxycycline during the initial acquisition phase of conditioning: under these conditions animals showed reinstatement of CPP to the degree observed in GFP-treated animals given the priming dose of cocaine (Fig. 3B'; between subject factor compared to LVGFP $p>0.243$; between subject factor compared to regimen without doxycycline $p<0.005$; and between subject factor compared to groups fed doxycycline in acquisition $p<0.003$, respectively). These data once more indicate that UPA expression during acquisition exerts effects that not only enhance the development of CPP (see Fig. $1 \mathrm{~A}^{\prime}$ ), but also endow animals with heightened responsiveness to cocaine, such that prior evidence of learning returns in a more robust form.

To further test this hypothesis, an uPA-specific inhibitor, B428 [35-37] was injected into the animals after establishment of CPP. Animals treated with either LV-GFP or LV-uPA, were condi-
No Doxy
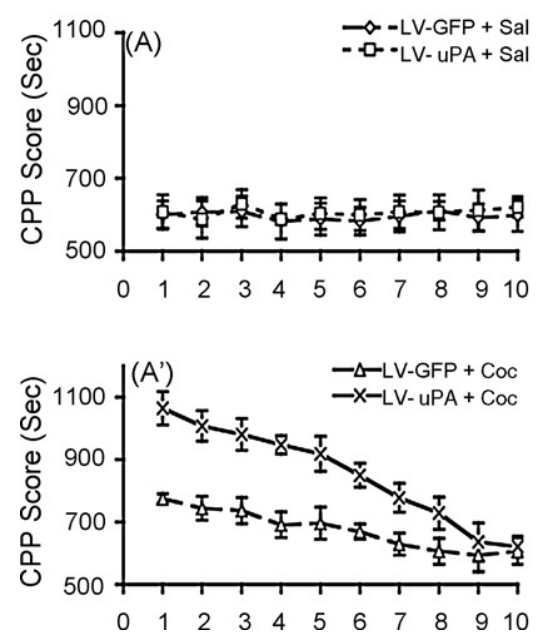

Doxy in Acquisition
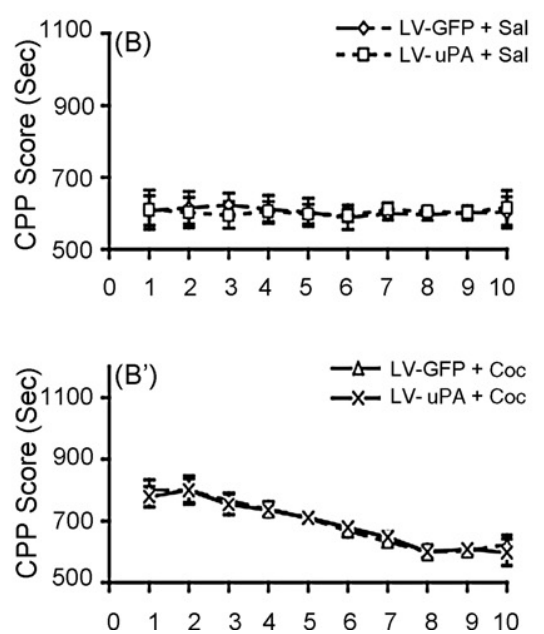

Doxy in Expression
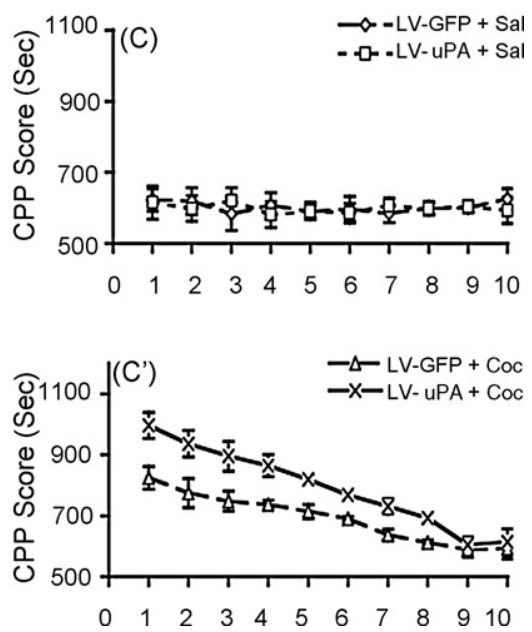

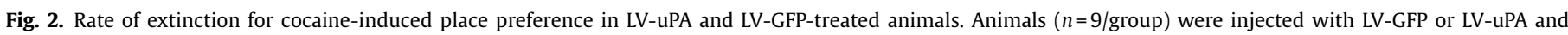

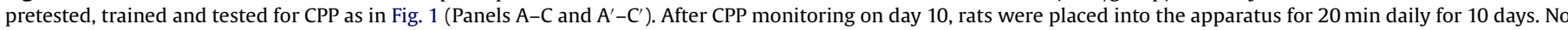

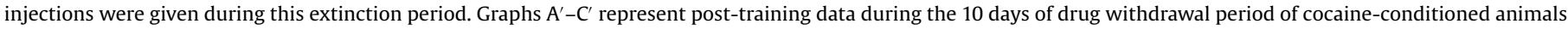
and start at higher levels than graphs $\mathrm{A}-\mathrm{C}$ that represent post-training data from saline-conditioned control animals. Values indicate means \pm S.E.M. 

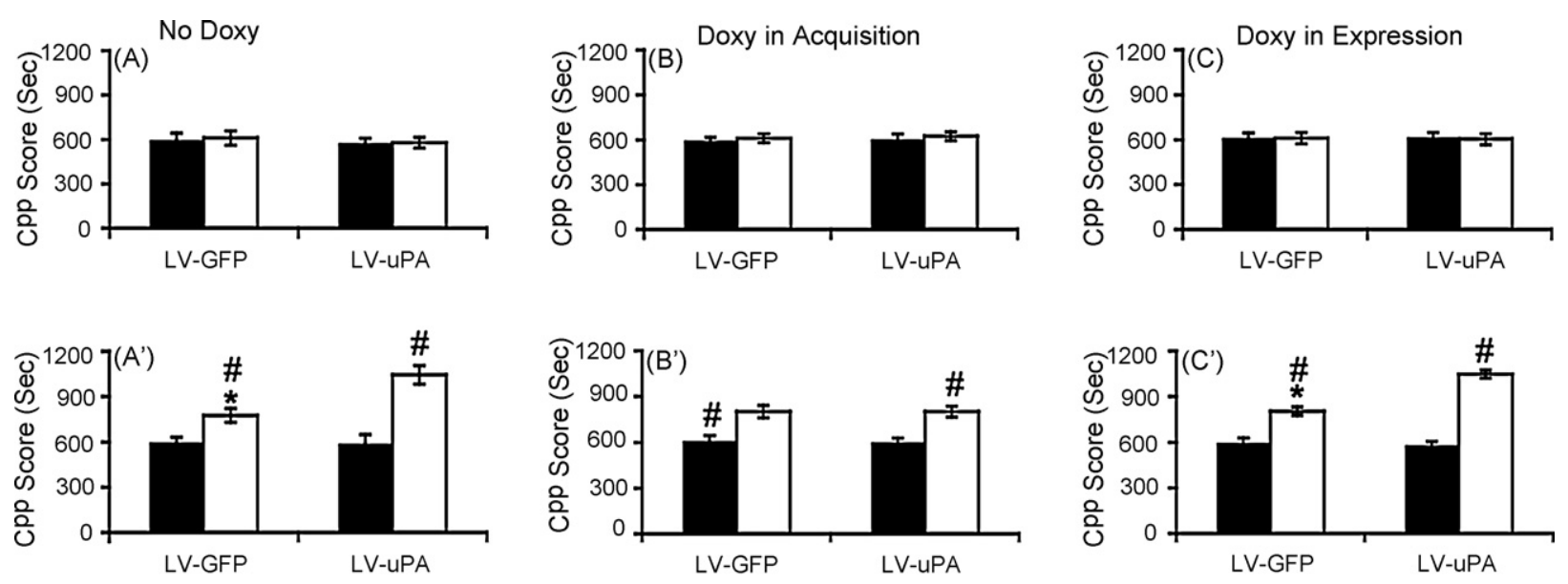

Saline-Conditioned animals

Cocaine-Conditioned animals

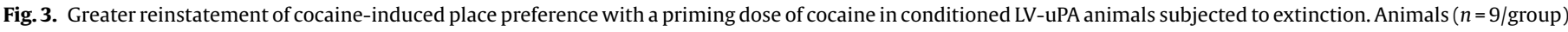

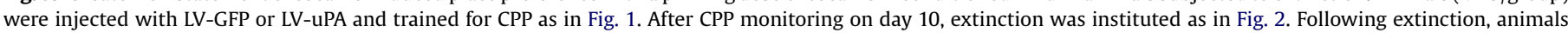

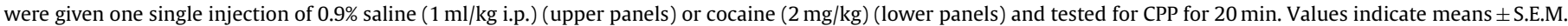
${ }^{*} p<0.05$ compared to LV-uPA injected animals; $\# p<0.05$ compared to saline-conditioned animals.
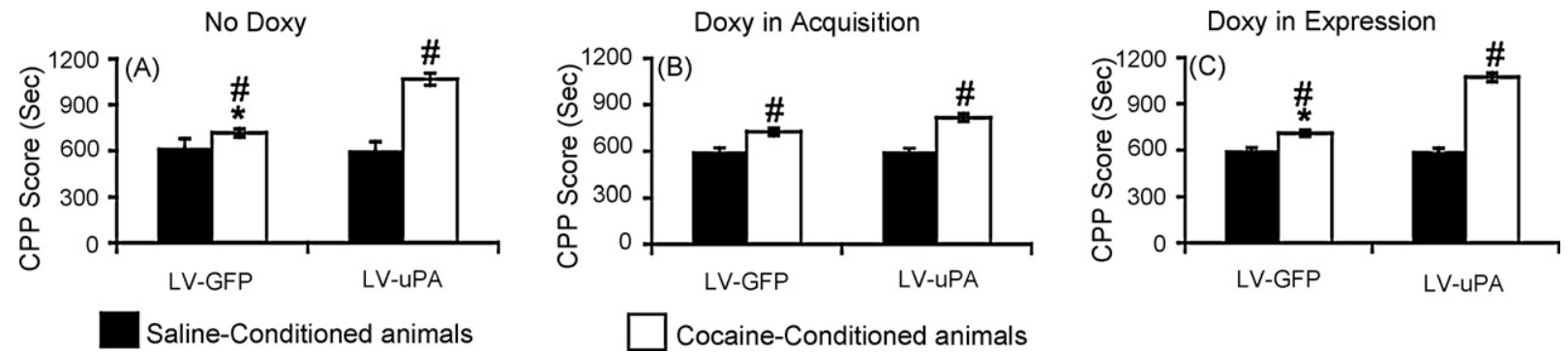

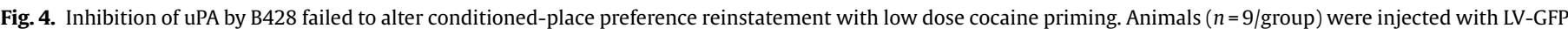

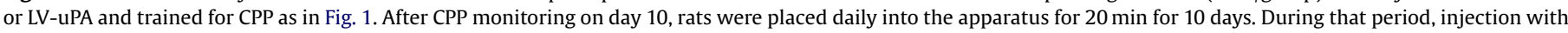

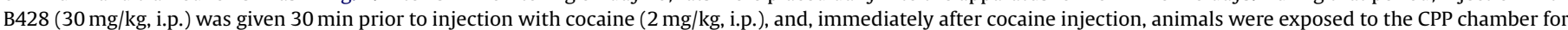
20 min preference testing. Values indicate means \pm S.E.M. ${ }^{*} p<0.05$ compared to LV-uPA injected animals; \#p<0.05 compared to saline-conditioned animals.

tioned for place preference and, after establishment of CPP, they were submitted to a 10-day extinction period. Thereafter uPA activity was inhibited by injecting B428 (30 mg/kg i.p.) $30 \mathrm{~min}$ prior to CPP monitoring upon priming injection of a low dose of cocaine $(2 \mathrm{mg} / \mathrm{kg})$. Between subjects analysis revealed significant changes $\left(F_{(11,120)}=102.73 ; p<0.0001\right)$. As shown in Fig. 4, GFP-treated animals displayed slight but significant place preference after B428 treatment (between subject factor $F_{(5,60)}=23.407$; $p<0.005$ ), irrespective of the doxycycline regimen given to these animals during the establishment of CPP. In addition, uPA-treated animals again immediately showed strong CPP reinstatement upon low dose cocaine priming, although uPA activity was fully inhibited under these conditions (between subject factor $F_{(5,60)}=178.515$; $p<0.0001$ ). Again animals, which had been fed doxycycline only during the acquisition phase, but not during expression, displayed no difference compared to GFP-treatment animals under similar conditions ( $p>1.00$; Fig. 4B). If expressed during acquisition, uPA promotes association of the drug with the environment, even if
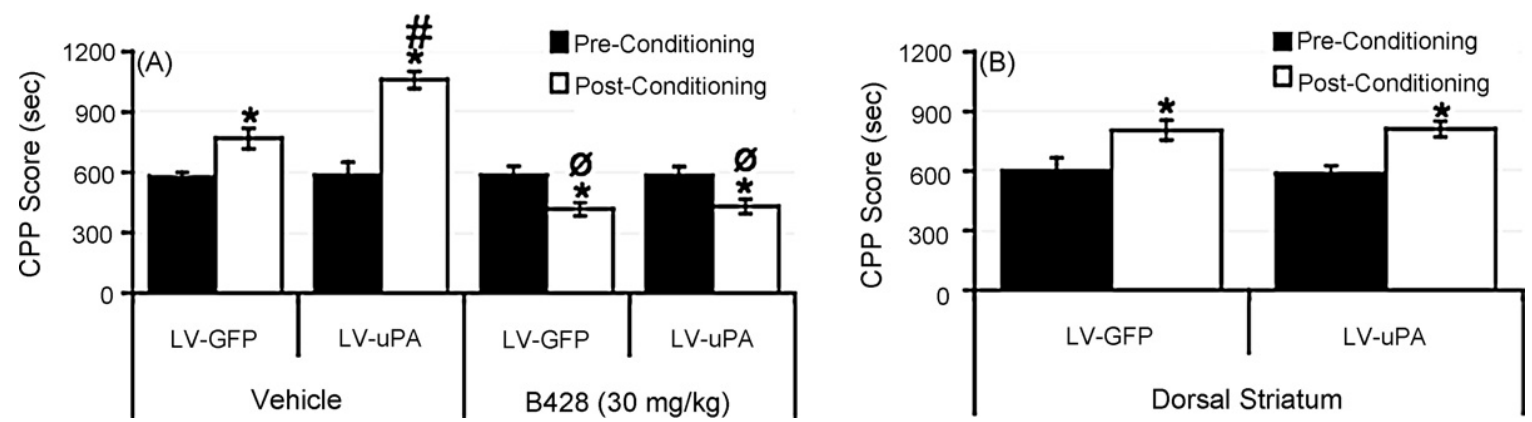

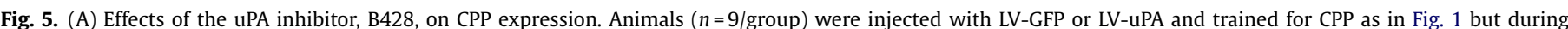

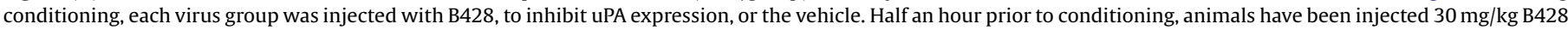

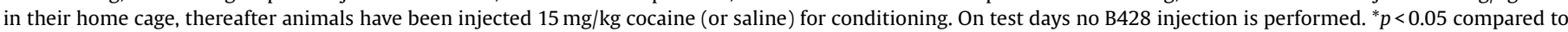

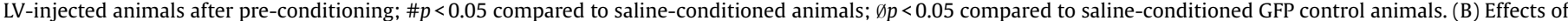

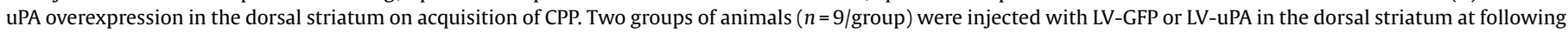

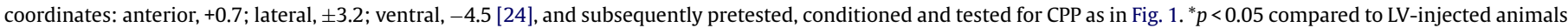
after pre-conditioning. 
it was no longer expressed at later stages (between subject factor $p<0.001$ vs. doxycycline fed animals). The inhibition of uPA by B428 occurs for both endogenous (in LV-GFP-treated animals) as well as ectopic uPA (in LV-uPA-treated animals). Therefore, as an alternative to using doxycycline, and in order to determine the role of endogenous uPA, the effect of B428 was assessed in animals subjected to cocaine conditioning (Fig. 5A). The results showed that B428 administration during acquisition suppresses CPP to below that of preconditioning. Blockade of endogenous uPA (GFP-treated animals) and exogenous uPA (in LV-uPA-treated group) during acquisition altered expression of cocaine-induced $\operatorname{CPP}\left(F_{(5,60)}=50.76 ; p<0.001\right)$. CPP is in fact augmented in LV-uPAinjected animals when vehicle is given, but there is no CPP in both GFP and uPA groups when B428 was injected. This indicates that suppressing endogenous uPA activity during acquisition alters CPP expression, which agrees with the finding that doxycycline inhibition of ectopic uPA during acquisition does alter CPP expression.

Furthermore, another group of animals was treated in the dorsal striatum, to better assess the specificity of the observed behavioral effects with respect to the NAc (Fig. 5B). Clearly overexpression of uPA in the dorsal striatum does not augment CPP upon cocaine conditioning, compared to controls $\left(F_{(5,60)}=1.22 ; p>0.521\right)$. This indicates that the behavioral changes observed upon overexpression of uPA are probably very related to the NAc. Further studies should be necessary to test this hypothesis.

In order to assess whether cocaine-induced place preference could be retained after a prolonged period of withdrawal from drug and drug-associated contexts, animals treated either LV-GFP or LV-uPA were trained for conditioned-place preference, then maintained in their home cages for 5 weeks, without further training and without drug injections. After this withdrawal period, animals were placed into the CPP set-up and place preference was measured. As shown in Fig. 6, animals displayed enhanced CPP scores $\left(F_{(11,120)}=119.79 ; p<0.0001\right)$, while saline-conditioned animals displayed no preference (Fig. $6 \mathrm{~A}-\mathrm{C} ; F_{(5,60)}=0.27 ; p>0.93$ ). In contrast, animals conditioned with cocaine showed enhanced CPP scores $\left(F_{(5,60)}=79.22 ; p<0.001\right)$, with LV-GFP-injected animals still spending a statistically significant amount of time in the drug compartment following reinstatement (Fig. $5 ; F_{(5,60)}=14.85 ; p<0.03$ ). In contrast, LV-uPA-treated animals spent more than $80 \%$ of the time in the drug compartment, but only if uPA had been expressed during the acquisition phase of the initial CPP training $\left(F_{(5,60)}=159.48\right.$; $p<0.0001$; Fig. $6 \mathrm{~A}$ and $\mathrm{C}$ ). If uPA expression was blocked during acquisition, reinstatement of place preference was not significantly different from GFP-treated animals ( $p>0.986$; Fig. 6B).

\subsection{Immunohistochemistry, real-time RNA quantification and SDS-PAGE gel zymography of uPA}

As shown in Fig. 7, the observed behavioral changes appear to be related to the expression of uPA in the injected sites. In the presence of doxycycline (either in acquisition or in expression of $\mathrm{CPP}$ ), uPA expression in the NAc is very low, corresponding to cocaine-induced endogenous uPA expression (Fig. 7A). Quantitative RT-PCR in these regions showed no significant changes in uPA mRNA expression in GFP-treated animals on the doxycycline regimen, compared to a normal non-doxycycline drinking water regimen. In LV-uPA-treated animals, uPA expression was 2.9-fold higher under the normal drinking regimen, compared to the doxycycline regimen (Fig. 7B). These changes are reflected in protein changes observed in immunohistochemistry (Fig. 7A).

It is also very likely that behavioral changes are associated with the active enzyme, as shown by zymography (Fig. 7C). Zymograms show two bands, a major bright one (at ca. $46 \mathrm{kDa}$ ), corresponding to the high-MW form of uPA, and minor bands (ca. $35 \mathrm{kDa}$ ) from a lower MW form of UPA. In the presence of doxycycline either in acquisition or in expression of CPP, but also in presence of B428, all groups displayed no active uPA. However, in the absence of doxycycline, but also during cocaine priming, LV-GFP-treated animals display no significant enzyme activity, compared to LV-uPA-treated animals where enzyme activity was very strong, in good correlation with observed behavioral data. This is also found upon reinstatement. These data strongly indicate that the active form of UPA is involved in observed behavioral changes.

\section{Discussion}

The goal of the current work was to determine the impact of uPA overexpression on CPP acquisition, extinction and/or reinstatement. The results showed that uPA overexpression in the NAc exerted a significant impact on cocaine-induced CPP and augmented CPP, and led to a more robust re-enlistment of CPP following extinction. The effect was abolished if overexpression was turned off with doxycycline. These effects have been generated by ectopic increases of UPA, and would have been more conclusive about the role of endogenous uPA if silencing of naturally produced uPA was produced, which is a question for future investigations. Nevertheless results are clearly indicate that excess uPA localized to the NAc promotes the development of cocaine-induced CPP. In contrast, when endogenous uPA was inhibited during acquisition, using B428, animals displayed no CPP. Therefore, given that animals with uPA lentivirus showed effects above and beyond the control virus manipulation (GFP), it is clear that increased uPA expression with repeated drug exposure produces conditions for enhanced acquisition of cocaine-induced CPP. Moreover, this overexpression appears to have a localized effect, since infusion of LV-uPA into the dorsal striatum was without significant effect on the development of CPP. Therefore, the present findings suggest that the impact of uPA in the NAc is critical to uPA-induced augmentation of cocaine-induced CPP.
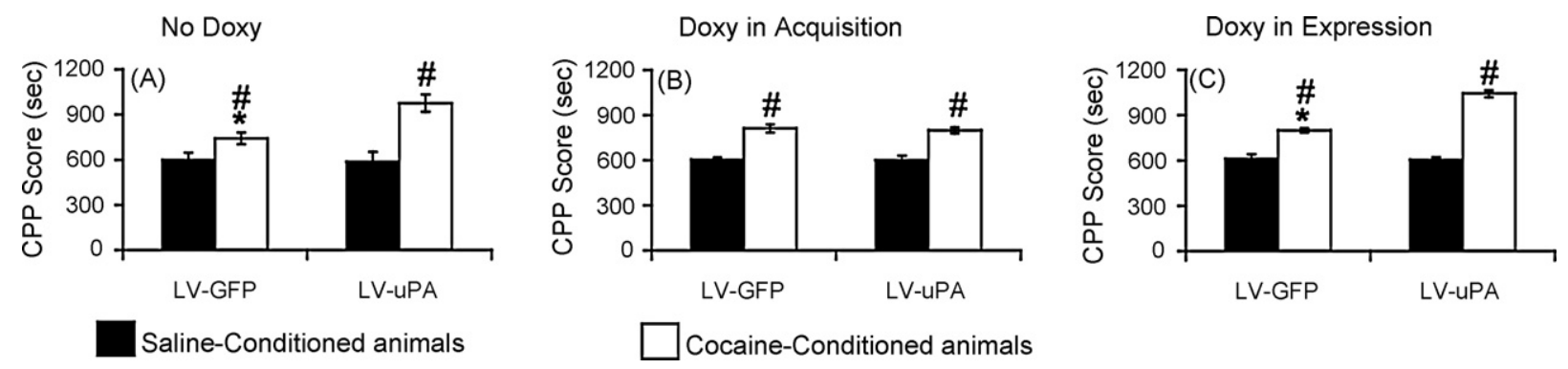

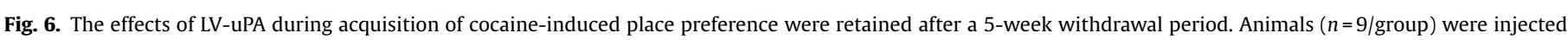

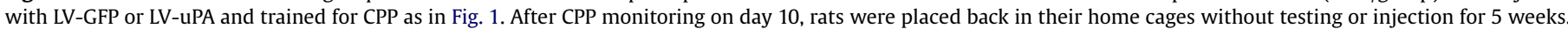

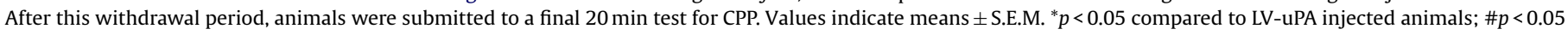
compared to saline-conditioned animals. 

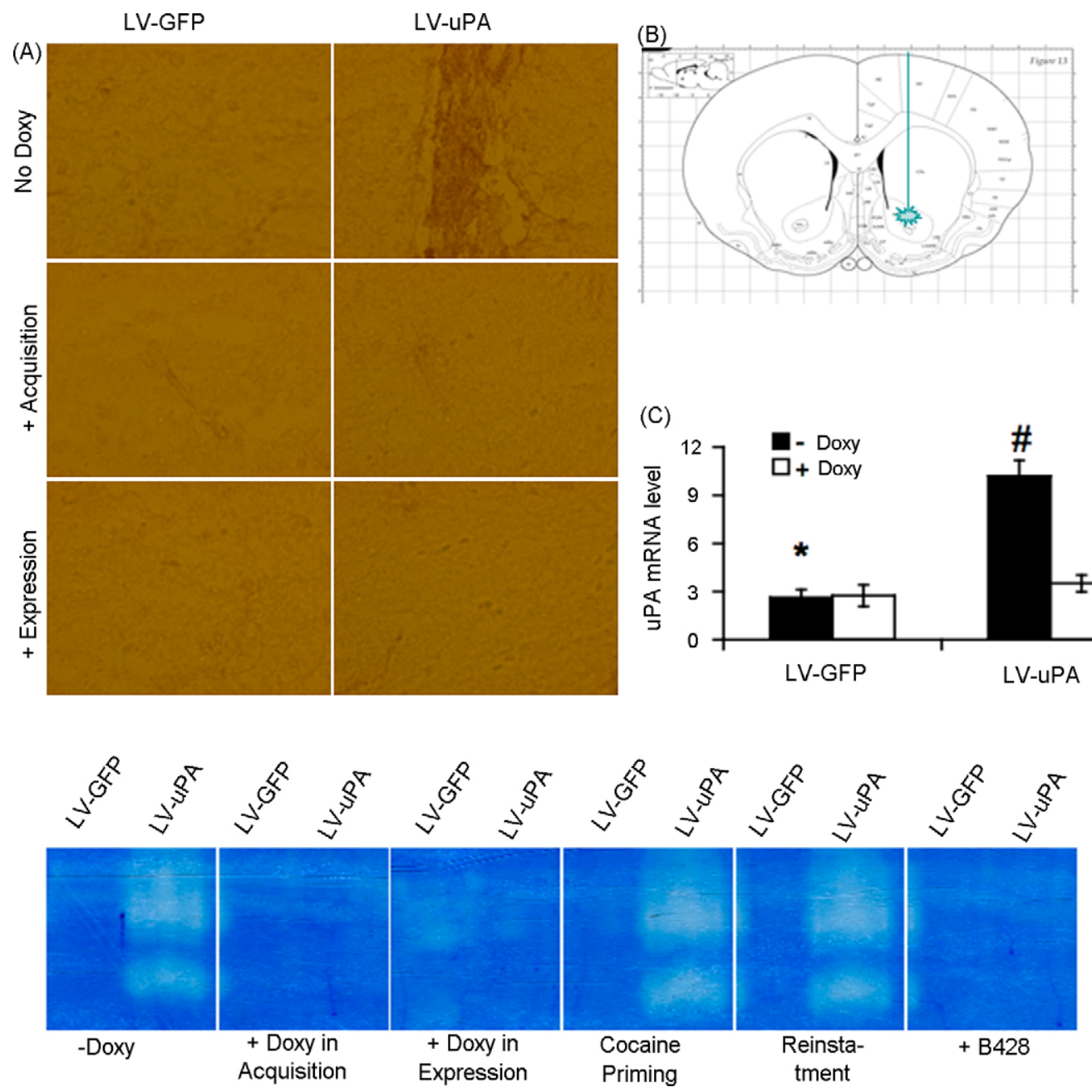

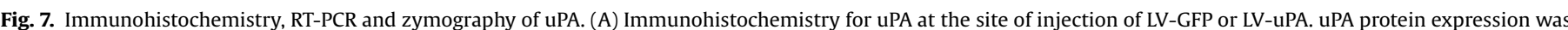

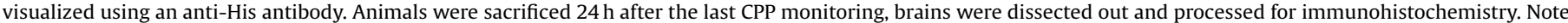

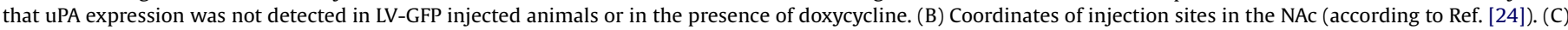

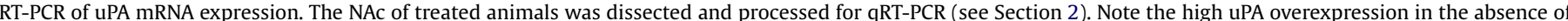

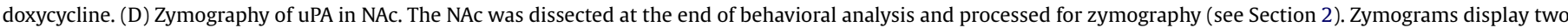

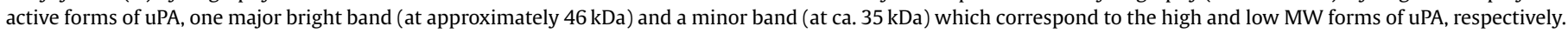

It is noteworthy that the LV-GFP groups conditioned with cocaine showed only weak, but statistically significant, development of place preference. Therefore, it is possible that the enhancing effects of uPA overexpression operate in the context of suboptimal development of CPP. Needless to say, uPA overexpression shifted preference to $90 \%$ to that of the saline-associated context. Therefore, there is little room for further augmentation in the CPP paradigm, and consequently, other procedures, such as self-administration may be better approaches for determining whether suboptimal circumstances for drug-reinforced behavior are enhanced by uPA. Furthermore, the fact that priming in uPA animals led to stronger reinstatement of preference speaks either to greater retention or greater rewarding effects of cocaine.

When uPA expression was inhibited by doxycycline during acquisition of CPP, animals no longer demonstrated evidence of having shown a greater or stronger association of the environment with cocaine. Doxy has no effects on endogenous uPA expression, since endogenous uPA is not doxycycline regulatable and in our previous work we have shown that within approximately $8 \mathrm{~h}$ after the introduction of doxycycline in the drinking fluid, more than $90 \%$ of the LV gene-suppressing doxycycline effects are reached, which has also been confirmed at the protein level Bahi et al. [12,20], and has been repeatedly observed in other experiments in our laboratory (unpublished data).

The rate of extinction was the same for all cocaine groups no matter what uPA treatment they received. In all cases it took approximately 6 days of extinction trials for a $50 \%$ reduction in CPP. The greater number of sessions needed to abolish CPP in uPA overexpressing rats was merely due to a higher starting point, but not to a delay in extinction, implying that uPA overexpression probably does not cause any alteration in extinction. However, after extinction, priming with low doses of cocaine reinstated place preference.

Several studies have shown that reinstatement of cocaineseeking behavior occurs after drug priming [38,39], and the drug itself triggers craving in human addicts $[40,41]$. Infusion of FN-439, a broad-spectrum MMP inhibitor, prevented cocaine-mediated CPP acquisition, blocked reinstatement of cocaine CPP and suppressed subsequent cocaine-primed reinstatement [42]. This is in full agreement with our finding using B428, a specific uPA inhibitor. Indeed, one goal of the present work was to test whether an inhibitor of uPA activity would also impair the acquisition of cocaine-induced CPP behavior. B428, a potent and specific uPA inhibitor that blocks both endogenous (in LV-GFP-treated animals) and ectopic uPA (in LV-uPA-treated animals) prevented the development of aug- 
mented CPP in LV-uPA animals, but did not affect drug-induced CPP reinstatement after extinction if LV-uPA had been active during acquisition. Together these data clearly indicate that uPA plays an important role in the acquisition but not expression of cocaineinduced conditioned-place preference. By virtue of augmenting the preference to a cocaine-associated context, the overexpression of uPA prolongs, but does not maintain, the behavioral inclination for exploring such a context in the absence of further cocaine treatment (as demonstrated by normal extinction). That is, after 5 weeks of withdrawal, CPP was still evident to a greater degree in LV-uPA animals. Therefore, while the presence of uPA overexpression may not produce resistance to extinction, animals appeared to show retention of the learning experience, as well as increased susceptibility to the reinstating effects of cocaine, as already mentioned earlier. It would be of interest to determine whether other potential influences such as stress might have a similar effect in reinstating CPP in LV-uPA animals previously conditioned with cocaine.

Urokinase plaminogen activator is an extracellular serine protease, which is expressed in most brain regions in the CNS [1,43-45] and exerts its main enzymatic actions by converting inactive precursor plasminogen to the active protease plasmin [46-48] and by degrading certain components in extracellular matrix, such as laminin [47,49-53]. The role of uPA for extracellular matrix degradation and dendritic spine dynamics has been well established [54,55]. In turn, plasmin plays an important role in neurite extension and synaptic remodeling by altering the cell-matrix interaction [56-58]. Its localized expression during neuronal development suggests that plasmin-mediated proteolysis facilitates neurite outgrowth and cell migration [59,60]. Plasmin regulates a cascade of extracellular proteolytic activities involved in longterm potentiation and depression [52,61-63] or in learning and memory [63-66]. Endogenous uPA may also regulate synaptic plasticity through mechanisms independent of plasmin or laminin, such as mediating an interaction between microglia and dopaminergic neurons, in analogy to mechanisms proposed for tPA [67].

Activity-dependent synaptic plasticity and remodeling of the mesolimbic dopaminergic system play a crucial role in the development of drug dependence $[3,10,68]$. Except from our previous studies, there is so far no mention of uPA on cocaine's reward, whereas in contrast tPA in amphetamine reward is gaining major insight. We have shown that uPA is strongly overexpressed after cocaine delivery under various paradigms (chronic, acute or binge) and strongly affects behavior [12,18,19]. The present study firmly consolidates these data and points to an important role of the plasmin system in chronic cocaine. Other studies have shown that the plasmin system releases dopamine in the NAc upon psychostimulants, which activates long-term synaptic plasticity and remodeling, and acutely participates in the rewarding effects of drugs such as methamphetamine or morphine $[13,14,16,17,69]$. It has been shown that tPA regulates nicotine-induced reward and dopamine release through protease activated receptor-1 [70]. Using the morphine self-administration procedure, the same group described very recently that tPA deficient mice display more morphine intake in a dose-dependent manner as compared to their wild type littermates [71]. However, under a progressive ratio schedule of morphine reinforcement, tPA null mice display a lower breaking point than wild-type mice [71]. These results and those reported here clearly support the hypothesis that plasminogen activators (tPA and uPA) play a central role in synaptic plasticity and drugassociated learning and memory phenomena.

There is some possibility that the dose of cocaine used in the present study could be aversive to some extent, as one would expect from sympathomimetic agents such as cocaine (a perplexing issue that Berridge, for example, has addressed). However, many other authors have used this same dose of cocaine in similar con- texts ([25,27-32]; Leri et al. [33,34]). In any case, while we did not have a robust effect on CPP in the LV-GFP animals, it was nevertheless in the predicted direction, as opposed to 'place aversion.' Whatever the neurobiological reasons for why highly arousing substances like cocaine result in dependent behavior, the dose that we used was nevertheless effective as an unconditioned stimulus. It is nevertheless possible that uPA rendered the "aversive" effects of cocaine less intense or even more tolerable. This question might be better addressed through self-administration studies where the operant behavior of the animal will provide an indication of whether uPA overexpression is altering the CNS response to cocaine.

A question that needs to be further addressed in future studies is whether there are neuroanatomical restrictions on the ability of uPA overexpression to augment cocaine-induced place preference. The current study was mainly restricted to overexpression in the NAc, based on previous studies that showed very strong locomotor changes when uPA was overexpressed in that brain region Bahi et al. $[12,20]$. However, it is possible that increased expression of uPA outside the NAcc might exert similar effects. This needs to be determined to confirm whether unique interactions between uPA and the neurons of the NAc are necessary and sufficient to produce an increase in place preference. Nevertheless, as already mentioned earlier, a control experiment in the dorsal striatum showed no significant behavioral changes, implying that unique interactions between uPA and the neurons of the NAc are necessary and sufficient to produce an increase in place preference. This however requires further detailed studies.

In conclusion, the present study suggests that uPA in the NAc facilitates and strengthens learning for a cocaine-associated context, even after extinction, and while animals are under the influence of a small priming dose of cocaine during reinstatement testing. Although not directly tested, these findings suggest that endogenous uPA may mediate cocaine-associated contextual learning.

\section{Acknowledgements}

Supported, by a Swiss National Foundation grants 3100-059350 and 3100AO-100686 (JLD) and PHS grants MH60706 (AWK) and NIEHS P30 ES05022 (AWK). The authors are also very grateful to $C$. Deforel-Poncet for her skilful assistance. Authors are grateful to $\mathrm{Mr}$. Littlefield BA from Eisai Research Institute, Andover, Massachusetts, USA, for providing B428.

\section{References}

[1] Masos T, Miskin R. Localization of urokinase-type plasminogen activator mRNA in the adult mouse brain. Brain Res Mol Brain Res 1996;35:139-48.

[2] Del Bigio MR, Hosain S, Altumbabic M. Localization of urokinase-type plasminogen activator, its receptor, and inhibitors in mouse forebrain during postnatal development. Int J Dev Neurosci 1999;17:387-99.

[3] Nestler EJ. Molecular basis of long-term plasticity underlying addiction. Nat Rev Neurosci 2001;2:119-28.

[4] Robinson TE, Kolb B. Persistent structural modifications in nucleus accumbens and prefrontal cortex neurons produced by previous experience with amphetamine. J Neurosci 1997; 17:8491-7.

[5] Robinson TE, Kolb B. Alterations in the morphology of dendrites and dendritic spines in the nucleus accumbens and prefrontal cortex following repeated treatment with amphetamine or cocaine. Eur J Neurosci 1999;11:1598-604.

[6] Robinson TE, Kolb B. Structural plasticity associated with exposure to drugs of abuse. Neuropharmacology 2004;47(Suppl 1):33-46.

[7] Koob GF. Drugs of abuse: anatomy, pharmacology and function of reward pathways. Trends Pharmacol Sci 1992;13:177-84.

[8] Wise RA. Neurobiology of addiction. Curr Opin Neurobiol 1996;6:243-51.

[9] Wise RA. Addiction becomes a brain disease. Neuron 2000;26:27-33.

[10] Koob GF, Sanna PP, Bloom FE. Neuroscience of addiction. Neuron 1998;21:467-76.

[11] Di Chiara G, Bassareo V. Reward system and addiction: what dopamine does and doesn't do. Curr Opin Pharmacol 2007;7:69-76. 
[12] Bahi A, Boyer F, Gumy C, Kafri T, Dreyer JL. In vivo gene delivery of urokinasetype plasminogen activator with regulatable lentivirus induces behavioral changes in chronic cocaine administration. Eur J Neurosci 2004;20:3473-88.

[13] Yamada K, Nagai T, Nabeshima T. Drug dependence, synaptic plasticity, and tissue plasminogen activator. J Pharmacol Sci 2005;97:157-61.

14] Iwata N, Inada T, Harano M, Komiyama T, Yamada M, Sekine Y, et al. No association is found between the candidate genes of t-PA/plasminogen system and Japanese methamphetamine-related disorder: a collaborative study by the Japanese Genetics Initiative for Drug Abuse. Ann N Y Acad Sci 2004;1025:34-8.

[15] Hyman SE. Addiction: a disease of learning and memory. Am J Psychiatry 2005;162:1414-22.

[16] Nagai T, Yamada K, Yoshimura M, Ishikawa K, Miyamoto Y, Hashimoto K, et al. The tissue plasminogen activator-plasmin system participates in the rewarding effect of morphine by regulating dopamine release. Proc Natl Acad Sci USA 2004; $101: 3650-5$

[17] Ripley TL, Rocha BA, Oglesby MW, Stephens DN. Increased sensitivity to cocaine, and over-responding during cocaine self-administration in tPA knockout mice. Brain Res 1999;826:117-27.

[18] Bahi A, Boyer F, Kafri T, Dreyer JL. Silencing urokinase in the ventral tegmental area in vivo induces changes in cocaine-induced hyperlocomotion. J Neurochem 2006;98:1619-31.

[19] Bahi A, Dreyer JL. Overexpression of plasminogen activators in the nucleus accumbens enhances cocaine-, amphetamine- and morphine-induced reward and behavioral sensitization. Genes Brain Behav 2008;7(2):244-56.

[20] Bahi A, Boyer F, Kafri T, Dreyer JL. CD81-induced behavioral changes during chronic cocaine administration: in vivo gene delivery with regulatable lentivirus. Eur J Neurosci 2004;19:1621-33.

[21] Bahi A, Boyer F, Bussard G, Dreyer JL. Silencing dopamine D3-receptors in the nucleus accumbens shell in vivo induces changes in cocaine-induced hyperlocomotion. Eur J Neurosci 2005;21:3415-26.

[22] Bahi A, Boyer F, Kolira M, Dreyer JL. In vivo gene silencing of CD81 by lentivira expression of small interference RNAs suppresses cocaine-induced behavior. J Neurochem 2005;92:1243-55.

[23] Naldini L, Blomer U, Gallay P, Ory D, Mulligan R, Gage FH, et al. In vivo gene delivery and stable transduction of nondividing cells by a lentiviral vector. Science 1996;272:263-7.

[24] Paxinos G, Watson C. The Rat Brain in Stereotaxic Coordinates. 4th edn. San Diego, USA: Academic Press; 1998

[25] Mueller D, Stewart J. Cocaine-induced conditioned place preference: reinstatement by priming injections of cocaine after extinction. Behav Brain Res 2000;115:39-47.

[26] Itzhak Y, Martin JL. Cocaine-induced conditioned place preference in mice: induction, extinction and reinstatement by related psychostimulants. Neuropsychopharmacology 2002;26:130-4.

[27] Bohn LM, Gainetdinov RR, Sotnikova TD, Medvedev IO, Lefkowitz RJ, Dykstra LA, et al. Enhanced rewarding properties of morphine, but not cocaine, in betaarrestin-2 knock-out mice. J Neurosci 2003;23:10265-73.

[28] Medvedev IO, Gainetdinov RR, Sotnikova TD, Bohn LM, Caron MG, Dykstra LA. Characterization of conditioned place preference to cocaine in congenic dopamine transporter knockout female mice. Psychopharmacology (Berl) 2005; $180: 408-13$

[29] Orsini C, Bonito-Oliva A, Conversi D, Cabib S. Susceptibility to conditioned place preference induced by addictive drugs in mice of the C57BL/ 6 and DBA/2 inbred strains. Psychopharmacology (Berl) 2005;181:327-36.

[30] Roma PG, Riley AL. Apparatus bias and the use of light and texture in place conditioning. Pharmacol Biochem Behav 2005;82:163-9.

[31] Becker A, Schmitz M, Grecksch G. Kindling modifies morphine, cocaine and ethanol place preference. Exp Brain Res 2006;168:33-40.

[32] Font L, Aragon CM, Miquel M. Ethanol-induced conditioned place preference, but not aversion, is blocked by treatment with $\mathrm{D}$-penicillamine, an inactivation agent for acetaldehyde. Psychopharmacology (Berl) 2006;184:56-64.

[33] Valjent E, Corbille AG, Bertran-Gonzalez J, Herve D, Girault JA. Inhibition of ERK pathway or protein synthesis during reexposure to drugs of abuse erases previously learned place preference. Proc Natl Acad Sci USA 2006;103:2932-7.

[34] Barot SK, Ferguson SM, Neumaier JF. 5-HT(1B) receptors in nucleus accumbens efferents enhance both rewarding and aversive effects of cocaine. Eur J Neurosci 2007;25:3125-31.

[35] Towle MJ, Lee A, Maduakor EC, Schwartz CE, Bridges AJ, Littlefield BA. Inhibition of urokinase by 4-substituted benzo[b]thiophene-2-carboxamidines: an important new class of selective synthetic urokinase inhibitor. Cancer Res 1993;53:2553-9.

[36] Evans DM, Sloan-Stakleff K. Suppression of the invasive capacity of human breast cancer cells by inhibition of urokinase plasminogen activator via amiloride and B428. Am Surg 2000;66:460-4.

[37] Todaro LB, Ladeda V, Bal de Kier Joffe E, Farias EF. Combined treatment with verapamil, a calcium channel blocker, and B428, a synthetic uPA inhibitor, impairs the metastatic ability of a murine mammary carcinoma. Oncol Rep 2003; 10:725-32.

[38] de Wit H, Stewart J. Reinstatement of cocaine-reinforced responding in the rat Psychopharmacology (Berl) 1981;75:134-43.

[39] Shaham Y, Shalev U, Lu L, De Wit H, Stewart J. The reinstatement model of drug relapse: history, methodology and major findings. Psychopharmacology (Berl) 2003;168:3-20.

[40] Ludwig AM, Wikler A. Craving and relapse to drink. Q J Stud Alcoho 1974;35:108-30.
[41] Jaffe JH, Cascella NG, Kumor KM, Sherer MA. Cocaine-induced cocaine craving. Psychopharmacology (Berl) 1989;97:59-64.

[42] Brown TE, Forquer MR, Cocking DL, Jansen HT, Harding JW, Sorg BA. Role of matrix metalloproteinases in the acquisition and reconsolidation of cocaineinduced conditioned place preference. Learn Mem 2007;14:214-23.

[43] Sappino AP, Madani R, Huarte J, Belin D, Kiss JZ, Wohlwend A, et al. Extracellular proteolysis in the adult murine brain. J Clin Invest 1993:92:679-85.

[44] Salles FJ, Strickland S. Localization and regulation of the tissue plasminogen activator-plasmin system in the hippocampus. J Neurosci 2002;22:2125-34.

[45] Ma Z, Webb DJ, Jo M, Gonias SL. Endogenously produced urokinase-type plasminogen activator is a major determinant of the basal level of activated ERK/MAP kinase and prevents apoptosis in MDA-MB-231 breast cancer cells. J Cell Sci 2001;114:3387-96.

[46] Vassalli JD, Sappino AP, Belin D. The plasminogen activator/plasmin system. J Clin Invest 1991;88:1067-72.

[47] Werb Z. ECM and cell surface proteolysis: regulating cellular ecology. Cell 1997;91:439-42.

[48] Fiumelli H, Jabaudon D, Magistretti PJ, Martin JL. BDNF stimulates expression, activity and release of tissue-type plasminogen activator in mouse cortical neurons. Eur J Neurosci 1999;11:1639-46.

[49] Tsirka SE, Gualandris A, Amaral DG, Strickland S. Excitotoxin-induced neuronal degeneration and seizure are mediated by tissue plasminogen activator. Nature 1995;377:340-4.

[50] Tsirka SE, Rogove AD, Bugge TH, Degen JL, Strickland S. An extracellular proteolytic cascade promotes neuronal degeneration in the mouse hippocampus. J Neurosci 1997; 17:543-52

[51] Goldfinger LE, Jiang L, Hopkinson SB, Stack MS, Jones JC. Spatial regulation and activity modulation of plasmin by high affinity binding to the $\mathrm{G}$ domain of the alpha 3 subunit of laminin-5. J Biol Chem 2000;275:34887-93.

[52] Nakagami Y, Abe K, Nishiyama N, Matsuki N. Laminin degradation by plasmin regulates long-term potentiation. J Neurosci 2000;20:2003-10.

[53] Tsirka SE. Tissue plasminogen activator as a modulator of neuronal survival and function. Biochem Soc Trans 2002;30:222-5.

[54] Fiorillo CD, Williams JT, Bonci A. D1-receptor regulation of synaptic potentials in the ventral tegmental area after chronic drug treatment. Adv Pharmacol 1998;42:1002-5.

[55] Oray S, Majewska A, Sur M. Dendritic spine dynamics are regulated by monocular deprivation and extracellular matrix degradation. Neuron 2004;44:1021-30.

[56] Moonen G, Grau-Wagemans MP, Selak I. Plasminogen activator-plasmin system and neuronal migration. Nature 1982;298:753-5.

[57] McGuire PG, Seeds NW. Degradation of underlying extracellular matrix by sensory neurons during neurite outgrowth. Neuron 1990;4:633-42.

[58] Shea TB, Beermann ML. Regulation of neuronal migration and neuritogenesis by distinct surface proteases. Relative contribution of plasmin and a thrombin-like protease. FEBS Lett 1992;307:190-4.

[59] Sumi Y, Dent MA, Owen DE, Seeley PJ, Morris RJ. The expression of tissue and urokinase-type plasminogen activators in neural development suggests different modes of proteolytic involvement in neuronal growth. Development 1992;116:625-37.

[60] Ware JH, DiBenedetto AJ, Pittman RN. Localization of tissue plasminogen activator mRNA in the developing rat cerebellum and effects of inhibiting tissue plasminogen activator on granule cell migration. J Neurobiol 1995;28:9-22.

[61] Frey U, Muller M, Kuhl D. A different form of long-lasting potentiation revealed in tissue plasminogen activator mutant mice. J Neurosci 1996;16:2057-63.

[62] Baranes D, Lederfein D, Huang YY, Chen M, Bailey CH, Kandel ER. Tissue plasminogen activator contributes to the late phase of LTP and to synaptic growth in the hippocampal mossy fiber pathway. Neuron 1998;21:813-25.

[63] Calabresi P, Napolitano M, Centonze D, Marfia GA, Gubellini P, Teule MA, et al Tissue plasminogen activator controls multiple forms of synaptic plasticity and memory. Eur J Neurosci 2000;12:1002-12.

[64] Meiri N, Masos T, Rosenblum K, Miskin R, Dudai Y. Overexpression of urokinasetype plasminogen activator in transgenic mice is correlated with impaired learning. Proc Natl Acad Sci USA 1994;91:3196-200.

[65] Madani R, Hulo S, Toni N, Madani H, Steimer T, Muller D, et al. Enhanced hippocampal long-term potentiation and learning by increased neuronal expression of tissue-type plasminogen activator in transgenic mice. EMBO J 1999; 18:3007-12.

[66] Nicole O, Docagne F, Ali C, Margaill I, Carmeliet P, MacKenzie ET, et al. The proteolytic activity of tissue-plasminogen activator enhances NMDA receptormediated signaling. Nat Med 2001;7:59-64.

[67] Nakajima K, Nagata K, Kohsaka S. Plasminogen mediates an interaction between microglia and dopaminergic neurons. Eur Neurol 1994;34(Suppl 3):10-6.

[68] Robinson TE, Berridge KC. Incentive-sensitization and addiction. Addiction 2001;96:103-14.

[69] Nagai T, Noda Y, Ishikawa K, Miyamoto Y, Yoshimura M, Ito M, et al. The role of tissue plasminogen activator in methamphetamine-related reward and sensitization. J Neurochem 2005;92:660-7.

[70] Nagai T, Ito M, Nakamichi N, Mizoguchi H, Kamei H, Fukakusa A, et al. The rewards of nicotine: regulation by tissue plasminogen activator-plasmin system through protease activated receptor-1. J Neurosci 2006;26:12374-83.

[71] Yan Y, Yamada K, Mizoguchi H, Noda Y, Nagai T, Nitta A, et al. Reinforcing effects of morphine are reduced in tissue plasminogen activator-knockout mice. Neuroscience 2007; 146:50-9. 